\title{
Oxycodone/Acetaminophen: The Tailoring Combination Treatment for Specific Clinical Profile of Opioid Well-Responsive Cancer Pain
}

This article was published in the following Dove Press journal: Cancer Management and Research

\section{Stefano De Santis, (ID)' Maria Domenica Simone, ${ }^{2}$ Sebastiano Mercadante, ${ }^{3}$ Rocco Domenico Mediati, ${ }^{4}$ Renato Vellucci, (iD ${ }^{4}$ Paolo Marchetti, ${ }^{5}$ Giuseppe Tonini, ${ }^{6}$ Arturo Cuomo, ${ }^{7}$ Augusto Caraceni, ${ }^{8}$ Silvia Natoli, (D) 9 Grazia Armento, ${ }^{6}$ Livio Blasi, ${ }^{10}$ Massimo Mammucari (iD) ${ }^{\prime \prime}$ \\ On behalf of the IOPS-MS Study Group}

'Palliative Care and Oncologic Pain Service, S. Camillo-Forlanini Hospital, Rome, Italy; ${ }^{2}$ Hematology and BMT Unit, S. Camillo-Forlanini Hospital, Rome, Italy;

${ }^{3}$ Anesthesia and Intensive Care \& Pain

Relief and Supportive Care, La

Maddalena, Palermo, Italy; ${ }^{4}$ Palliative Care and Pain Therapy Unit, Careggi Hospital, Florence, Italy; ${ }^{5}$ Molecular and Clinical Medicine Medical Oncology, La Sapienza University of Rome, Rome, Italy; ${ }^{6}$ Department of Medical Oncology, Campus Bio-Medico University of Rome, Rome, Italy; ${ }^{7}$ Anesthesiology,

Resuscitation, and Pain Therapy Department, National Cancer Institute, IRCCS Foundation, Naples, Italy; ${ }^{8}$ Palliative Care, Pain Therapy and Rehabilitation, National Cancer Institute, IRCCS Foundation, Milan, Italy;

${ }^{9}$ Department of Clinical Science and Translational Medicine - University of Rome Tor Vergata and Department of Emergency, Admission and Critical Area - Policlinic of Tor Vergata, Rome, Italy; ${ }^{10}$ Medical Oncology Unit, ARNAS Ospedale Civico Di Cristina Benfratelli, Palermo, Italy; " Primary Care Unit, ASL RMI, Rome, 00165, Italy

Correspondence: Stefano De Santis Email sdesantis@scamilloforlanini.rm.it
Background: International guidelines recommend moderate-to-severe cancer pain to be treated with strong opioids. However, pain management remains an unsolved matter, at least in the demanding oncology and palliative care setting. Although cancer pain consists of multiple components, which interact in complex ways where combination therapy can better intercept multiple pain characteristics, few studies have used a non-opioid/opioid association to exploit possible synergistic actions. Even the efforts of a recent approach emphasizing appropriate pain assessment and accurate classification to obtain personalized pain management have not produced a satisfactory analgesic strategy.

Objective: This analysis was intended to evaluate the effectiveness of the immediate release fixed combination of oxycodone/acetaminophen (OxyIR/Par) for the treatment of moderateto-severe intensity background pain used alone or in combination with other strong opioids in cancer patients with breakthrough cancer pain (BTcP). This is a secondary analysis of a wider observational, prospective, multicenter study [Italian Oncologic Pain multiSetting Multicentric Survey (IOPS-MS)] performed on 179 patients treated with opioids for cancer pain who received the fixed combination of oxycodone/acetaminophen (OxyIR/Par) for the treatment of background pain (BGP).

Results: Cancer patients with breakthrough cancer pain and controlled BGP (Background Pain) were classified according to the presence of analgesic therapy with tablets of fixed combination OxyIR/Par alone (group A, $n=120$ ) or tablets of fixed combination OxyIR/Par combined with other strong opioids (group $\mathrm{B}, \mathrm{n}=59$ ). Clinical features of group A were different to group B: higher mean Karnofsky Performance Status Index 70.3\% (95\% $\mathrm{CI}=67.2-73.5$; median $=70, \mathrm{CI}=60-80)$ vs $58.3(95 \% \mathrm{CI}=53.4-63.2 ;$ median $=50, \mathrm{CI}=45-70)$ $(P<0.001)$, and mainly group A patients were treated in an ambulatory setting $(55.0 \%$ group A vs $33.9 \%$ group $B)(\mathrm{p}<0.001)$. Both groups had managed BGP with similar mean dosages (group A: 12.0, CI=10.5-13.4; group B: 13.1, CI=11.0-15.1) and frequencies of OxyIR/Par alone for group A and in association to other opioids for group B, but Breakthrough cancer Pain (BTcP) exhibited different characteristics in the two groups, showing a lower mean intensity numerical rating scale (NRS) of $7.5(95 \% \mathrm{CI}=7.2-7.7$; median=7, $\mathrm{CI}=7-8$ group A) vs $7.9(95 \% \mathrm{CI}=7.6,8.2$; median $=8, \mathrm{CI}=7-9$ group $\mathrm{B})(P=0.04)$ and a higher percentage of patients had a faster onset, defined as the maximum intensity reached in less than 10 minutes, $81.7 \%(\mathrm{~N}=98)$ in group A vs $59.3 \%(\mathrm{n}=35)$ in group $\mathrm{B}(P=0.002)$.

Conclusion: This is the first analysis about the efficacy of an immediate-release fixed combination of OxyIR/Par in the real world for moderate-to-severe background cancer pain and breakthrough cancer pain. The oral fixed combination OxyIR/Par provided an adequate level of analgesia for moderate-severe background cancer pain, in a different cohort of cancer patients with different performance status, both in ambulatory and palliative 
settings. The low dosage of fixed combination OxyIR/Par was effective alone or in association with other opioids.

Keywords: analgesia, combination of oxycodone/acetaminophen, cancer pain, breakthrough cancer pain

\section{Introduction}

Managing chronic cancer pain in palliative care is a complicated matter, even with a pharmacological armamentarium constituted by non-opioid agents, notably acetaminophen (paracetamol) and nonsteroidal anti-inflammatory drugs (NSAIDs), and opioids. ${ }^{1}$ WHO guidelines defined the first milestone strategies for the management of cancer pain, such as preferred oral administrations, around the clock therapy, tailoring therapy, and the three steps ladder. ${ }^{1}$ However, recent cancer pain guidelines, starting from those mainstay strategies, suggest the use of a low dose of strong opioids in association with non-opioid drugs and/or adjuvants for moderate-to-severe pain. $^{2-4}$

However, various patients with moderate-to-severe pain do not receive adequate pain treatment. ${ }^{5}$ Cancer pain is heterogeneous and responsiveness to opioids can be variable and unpredictable, depending on patientrelated factors, drug-selective effects, and pain-related factors. ${ }^{6}$

Adverse effects, also, are likely to reduce patient compliance. Despite the widespread use of opioids treatment, unrelieved pain continues to be a substantial concern in cancer patients, and a common reason is represented by the inadequacy of analgesic therapy. ${ }^{5,7,8}$ Recently, multimodal analgesia has also been thoroughly studied, demonstrating that different drugs used together could have additive or synergistic effects, acting on different pain mechanisms it improves the efficacy on different types of pain (neuropathic and nociceptive pain). The fixed-dose combination of oxycodone and acetaminophen immediate-release formulation allows efficacy at lower individual opioid doses thanks to their synergistic mechanisms of action. ${ }^{9-12}$

In light of the above concept, studies of the oxycodone immediate-release/acetaminophen (OxyIR/Par) in a fixed combination have demonstrated the efficacy and versatile use in different acute and chronic non-oncologic pathologies characterized by moderate-to-severe pain, and different types of pain (nociceptive, neuropathic, and mixed). ${ }^{12-14}$ In a study on the cancer population, the fixed combination of oxycodone/acetaminophen has provided substantial benefits for the control of background pain on already pretreated patients with high doses of SR (slow release) opioids (OME 180-360 mg/day). ${ }^{15}$
European guidelines proposed the role of oxycodone/ acetaminophen at low doses starting from the traditionally second step of the WHO ladder. ${ }^{3}$

Oxycodone is widely available after oral administration and rapidly absorbed. It is principally a $\kappa$ receptor agonist and the activation of $\mathrm{k}$ opioids receptors activates the $\mu$ and $\mathrm{d}$ receptors through a cross-talk mechanism, which may be responsible for the analgesic effect of oxycodone. ${ }^{16}$ The oxycodone active metabolites, oxymorphone, and noroxycodone, are $\mu$ receptor agonists and they seem to have involvement in the analgesic effect, though primarily analgesia is relied on as the parent compound. ${ }^{16}$ Oxycodone action probably depends on the agonist activity in the spinal cord with an antinociceptive action on pain pathways. ${ }^{13,17}$ Acetaminophen presents high bioavailability and a good level of tolerability at therapeutic dosages. It's antipyretic/analgesic action is due to prostaglandins synthesis inhibition, probably at the central level, and to its action on other pathways, eg, activity on the cannabinoid receptor type 1 (CB1), to stimulation of the descending inhibitory serotonergic pathways at the spinal cord level. $^{13}$

The fixed-dose combination of oxycodone/acetaminophen immediate-release presents several clinical advantages: i) the two compounds act on different pain components; ii) fixed-dose combination offers pain relief with opioid-sparing effect; iii) oxycodone and acetaminophen have overlapping pharmacokinetic characteristics but different metabolisms, to the advantage of greater efficacy without risk of metabolic interaction; iv) fixed-dose simplifies dosing schedule, and v) increases compliance in chronic treatment.

Oxycodone immediate release is available in our country in oral tablets in different dosages $(5,10$, or $20 \mathrm{mg})$ in combination with acetaminophen at a fixed dose $(325 \mathrm{mg})$ (drug named Depalgos ${ }^{\mathcal{C}}$; Molteni Farmaceutici, Inc., Italy), here called OxyIR/Par. Although oxycodone in both immediate-release and modified-release formulations has been used for years as the opioid of choice for cancer pain management, the outcomes associated with low doses of oxycodone in fixed combination with acetaminophen have never been published. ${ }^{3,4,18,19}$

This analysis intends to evaluate, for the first time, the effectiveness of the OxyIR/Par combination in a real-world 
observation, for the treatment of moderate-to-severe intensity background cancer pain (BGP) used alone or in combination with other strong opioids in cancer patients with breakthrough cancer pain (BTcP). Moreover, the impact of the OxyIR/Par association on BTcP was assessed.

\section{Methods}

This was a secondary analysis of a previous observational, prospective, multicenter study, the IOPS-MS Study (Italian Oncologic Pain multiSetting Multicentric Survey). ${ }^{20}$ The research was carried out in accordance with the conditions of the Declaration of Helsinki, recommendations guiding physicians in biomedical research involving human subjects, and was approved by the independent ethic committee of Fondazione PTV Policlinico Tor Vergata Hospital of the University of Rome "Tor Vergata" (identifiers: Ethical Approval Letter No. 21/13 dated 20 Feb 2013). Written informed consent was obtained from each patient.

A total of 4,016 patients were enrolled during a period of 24 months as outpatient, inpatient, day-hospital, and recruited in palliative care, oncology, radiotherapy, and pain therapy settings. Patients had a diagnosis of cancer at any stage, a well-controlled and stable BGP (intensity $\leq 4$ NRS), and the presence of BTcP episodes of moderatesevere intensity. Results of the study have been previously reported elsewhere. ${ }^{20}$ The original study was approved by each local ethics committee and each patient provided written informed consent.

The inclusion criteria for the selection, according to the main study, were: age $\geq 18$ years, diagnosis of cancer at any stage, stable in the last week, and opioid analgesicwell-controlled background pain (BGP) with an intensity $\leq 4$ on a $0-10$ numerical scale (NRS) treated with the fixed combination of OxyIR/Par alone or in combination with other opioids for the treatment of cancer-related pain, and the presence of Breakthrough cancer Pain (BTcP) episodes of moderate-severe intensity, clearly distinguished from background pain. The definition of BTcP was a transitory pain exacerbation of moderate-to-severe intensity that occurs spontaneously or predictably, ${ }^{21-23}$ well distinguished from background pain. The diagnosis of BTcP was based on an algorithm previously reported. ${ }^{24}$ The main trial exclusion criteria were: unstable or pharmacological-uncontrolled background pain in the last week $(>4 /$ $10 \mathrm{NRS}$ ), lower pain intensity spikes ( $<5 / 10 \mathrm{NRS})$, and the incapability to be assessed. Patients meeting the inclusion criteria were consecutively surveyed.
The population was analyzed in order to investigate characteristics of the population, background pain, and BTcP. Age, gender, setting, primary cancer, and Karnofsky status were recorded. For pain, the following data were collected: average pain intensity of background pain (BGP) on an 11-point NRS scale from 0-10 in the last week and pain intensity on the day of assessment, opioids used for BGP and their doses, expressed as oral morphine equivalents (OME), BGP sites, the number of BTcP episodes/day, its mean intensity (on NRS scale), onset (as the time to reach the maximum spike intensity), the mean duration of untreated episodes, predictability, relieving factors, BTcP sites, and adverse reactions.

For this secondary analysis, 179 patients in treatment for BGP with OxyIR/Par, alone or in combination with other opioids, were extracted. Treatment was used according to the clinical practice.

\section{Statistics}

Clinical information was collected with an electronic clinical report form and, after checking and validating the data, they were analyzed. Descriptive statistics were made: average, standard deviation (SD) for continuous variables, and absolute and relative frequencies for categorical calculated variables. Descriptive analyses were conducted for subgroups. Chi-squared, mean and 95\% confidence interval (CI), Fisher's exact, and independentsample $t$-test were used to assess differences between the two groups, as appropriate.

\section{Results}

Starting from the 4,016 subjects of the original published study, 179 cancer patients receiving the oral fixed combination of OxyIR/Par for the treatment of moderate-tosevere intensity BGP were evaluated here.

Of this population, 120 (group A; 67.0\%) patients were in treatment with OxyIR/Par as their only analgesic therapy, while 59 (group B; 33.0\%) patients received therapy with OxyIR/Par associated with other strong opioid drugs. The general characteristics of the two groups of patients are detailed in Table 1.

In both groups the mean age was about 68 years and male gender was more represented $(56.7 \%$ in group A, $52.5 \%$ in group B). The most prevalent disease group was lung (26.3\%), followed by gastrointestinal (16.8\%), and breast disease $(15.6 \%)$, and $83.2 \%$ of the patients were metastatic.

In group A, OxyIR/Par BGP was well controlled with an average intensity in the previous week of 3.2 
Table I The General Characteristics of the Population Treated with OxyIR/Par for Background Pain Alone (Group A, n=120) and in Combination with Other Opioid Drugs (Group B, n=59)

\begin{tabular}{|c|c|c|c|}
\hline & & Group A (120) & Group B (59) \\
\hline \multirow[t]{2}{*}{ Gender $^{a}$} & Male & $68(56.7 \%)$ & 31 (52.5\%) \\
\hline & Female & 52 (43.3\%) & 28 (47.5\%) \\
\hline \multirow[t]{2}{*}{ Age (years) ${ }^{a}$} & Median (IQR) & $68(59,75)$ & $67(62,75)$ \\
\hline & Mean $(95 \% \mathrm{Cl})$ & $66.7(64.7-68.8)$ & $66.5(63.2-69.7)$ \\
\hline \multirow[t]{2}{*}{ Karnofsky } & Median (IQR) & $70(60,80)$ & $50(45,70)^{\mathrm{b}}$ \\
\hline & Mean $(95 \% \mathrm{Cl})$ & $70.3(67.2-73.5)$ & $58.3(53.4-63.2)^{\mathrm{b}}$ \\
\hline \multirow[t]{4}{*}{ Setting $^{\mathbf{b}}$} & Oncology & $6 \mathrm{I}(50.8 \%)$ & $13(22.0 \%)^{b}$ \\
\hline & Pain therapy & 43 (35.8\%) & 15 (25.4\%) \\
\hline & Radiotherapy & $0(0.0 \%)$ & $2(3.4 \%)$ \\
\hline & Palliative care & $16(13.3 \%)$ & $29(49.2 \%)^{b}$ \\
\hline \multirow[t]{5}{*}{ Place of visit ${ }^{b}$} & Hospital inpatient & 27 (22.5\%) & $5(8.5 \%)^{b}$ \\
\hline & Outpatients & $66(55.0 \%)$ & $20(33.9 \%)^{b}$ \\
\hline & Day hospital & II (9.2\%) & $8(13.6 \%)$ \\
\hline & Hospice & $2(1.7 \%)$ & I (I.7\%) \\
\hline & Home care & 14 (II.7\%) & $25(42.4 \%)^{b}$ \\
\hline \multirow{9}{*}{ Primary tumor $^{a}$} & Lung & $36(30.0 \%)$ & II (18.6\%) \\
\hline & Gastrointestinal $^{c}$ & $23(19.2 \%)$ & 7 (11.9\%) \\
\hline & Breast & $19(15.8 \%)$ & $9(15.3 \%)$ \\
\hline & Pancreas & $6(5.0 \%)$ & $4(6.8 \%)$ \\
\hline & Urological & $5(4.2 \%)$ & $6(10.2 \%)$ \\
\hline & Prostate & $8(6.7 \%)$ & II (I8.6\%) \\
\hline & Head-neck & $10(8,3 \%)$ & $2(3.4 \%)$ \\
\hline & Gynecologic & $2(1.7 \%)$ & $3(5.1 \%)$ \\
\hline & Hematological & $5(4.2 \%)$ & $2(3.4 \%)$ \\
\hline \multirow[t]{2}{*}{ Disease $^{a}$} & Locoregional & $29(24.2 \%)$ & $10(17.0 \%)$ \\
\hline & Metastatic & $96(80.0 \%)$ & $53(89.8 \%)$ \\
\hline \multirow[t]{9}{*}{ Metastases $^{\mathbf{a}}$} & Liver & $26(21.7 \%)$ & $16(27.1 \%)$ \\
\hline & Abdominal lymph nodes & $13(10.8 \%)$ & $8(13.6 \%)$ \\
\hline & Chest lymph nodes & 17 (14.2\%) & $10(16.9 \%)$ \\
\hline & Bones & $60(50.0 \%)$ & $33(55.9 \%)$ \\
\hline & Peritoneum & $7(5.8 \%)$ & I (I.7\%) \\
\hline & Lungs & $21(17.5 \%)$ & 14 (23.7\%) \\
\hline & CNS & $0(0.0 \%)$ & $3(5.1 \%)$ \\
\hline & Adrenal & $2(1.7 \%)$ & $2(3.4 \%)$ \\
\hline & Other & $13(10.8 \%)$ & I (II.9\%) \\
\hline
\end{tabular}

Notes: ${ }^{a} \mathrm{P}>0.05$ (group A vs group B). ${ }^{b} \mathrm{P}<0.00 \mathrm{I}$ (group A vs group B). ${ }^{\mathrm{c} G a s t r o i n t e s t i n a l ~ i n c l u d e s: ~ e s o p h a g u s, ~ s t o m a c h, ~ c o l o n i c, ~ r e c t u m, ~ a n u s, ~ l i v e r ~ a n d ~ b i l i a r y ~ c a n c e r s . ~}$

NRS (95\% CI=3.0-3.3) and there was no statistical difference with group B, with BGP controlled by OxyIR/Par and other opioids (2.9 NRS on average; $95 \% \mathrm{CI}=2.7-3.2)(P=0.17)$. Pain intensity on the day of assessment was $3.3 \mathrm{NRS}(95 \% \mathrm{CI}=3.0-3.6)$ with persistent pain relief for an average of 1.2 months (95\% CI $=0.9-1.5)$, and there was no statistical difference with group B pain intensity of the day of assessment, which was $3.2 \mathrm{NRS}(95 \% \mathrm{CI}=2.6-3.7)$ and with the length of persistent pain relief being an average of 2.0 months $(95 \% \mathrm{CI}=1.0-3.1) \quad(P=0.13)$ (Table 2). In group $\mathrm{B}$, the treatment of BGP with Oxy/Par was associated with other opioids such as oxycodone slowrelease, alone $(6,10.2 \%)$ or in combination with naloxone $(26,44.1 \%)$ or fentanyl transdermal therapeutic system (TTS) (17, 28.8\%)(Table 3).

According to the objective clinical examination, the global prevailing mechanism of BGP was mixed $(n=102$, 
Table 2 Background Pain and BTcP Characteristics in the Population Treated Only with OxylR/Par for Background Pain ( $\mathrm{n}=120)$ and in Combination with Other Opioid Drugs $(n=59)$

\begin{tabular}{|c|c|c|c|}
\hline & & Group A $(n=120)$ & Group B $(n=59)$ \\
\hline $\begin{array}{l}\text { Background pain } \\
\text { Intensity during last week }\end{array}$ & $\begin{array}{l}\text { Median }(\text { IQR }) \\
\text { Mean }(95 \% \mathrm{Cl})\end{array}$ & $\begin{array}{l}3(3,4) \\
3.2(3.0-3.3)\end{array}$ & $\begin{array}{l}3(2,4) \\
2.9(2.7-3.2)\end{array}$ \\
\hline $\begin{array}{l}\text { Background pain } \\
\text { Intensity on day of assessment }{ }^{a}\end{array}$ & $\begin{array}{l}\text { Median }(\text { IQR }) \\
\text { Mean }(95 \% \mathrm{Cl})\end{array}$ & $\begin{array}{l}3(2,4) \\
3.3(3.0-3.6)\end{array}$ & $\begin{array}{l}3(2,4) \\
3.2(2.6-3.7)\end{array}$ \\
\hline Pain duration (months) & $\begin{array}{l}\text { Median (IQR) } \\
\text { Mean }(95 \% \mathrm{Cl})\end{array}$ & $\begin{array}{l}1.8(1.0-2.6) \\
2.6(2.0-3.2)\end{array}$ & $\begin{array}{l}1.1(0.6-3.1) \\
3.5(1.6-5.3)\end{array}$ \\
\hline BGP Pain sites $^{a}$ & $\begin{array}{l}\text { Abdominal } \\
\text { Lower limbs } \\
\text { Pelvis } \\
\text { Cervical spine } \\
\text { Dorsal spine } \\
\text { Lumbar spine } \\
\text { Sacral spine } \\
\text { Chest }\end{array}$ & $\begin{array}{l}31(25.8 \%) \\
19(15.8 \%) \\
10(8.3 \%) \\
7(5.8 \%) \\
23(19.2 \%) \\
26(21.7 \%) \\
6(5.0 \%) \\
29(24.2 \%)\end{array}$ & $\begin{array}{l}10(16.9 \%) \\
11(18.6 \%) \\
12(20.3 \%) \\
6(10.2 \%) \\
13(22.0 \%) \\
22(37.3 \%) \\
4(6.8 \%) \\
8(13.6 \%)\end{array}$ \\
\hline Pain type ${ }^{a}$ & $\begin{array}{l}\text { Mixed } \\
\text { Neuropathic } \\
\text { Nociceptive }\end{array}$ & $\begin{array}{l}68(56.7 \%) \\
20(16.7 \%) \\
32(26.6 \%)\end{array}$ & $\begin{array}{l}34(57.6 \%) \\
2(3.4 \%) \\
23(39.0 \%)\end{array}$ \\
\hline Pain therapy taken from $[\text { months }]^{a}$ & $\begin{array}{l}\text { Median (IQR) } \\
\text { Mean }(95 \% \mathrm{Cl})\end{array}$ & $\begin{array}{l}0.8(0.4-1.3) \\
1.2(0.9-1.5)\end{array}$ & $\begin{array}{l}1.0(0.3-2.0) \\
2.0(1.0-3.1)\end{array}$ \\
\hline BTP (episodes/day) ${ }^{\mathbf{a}}$ & $\begin{array}{l}\text { Median (IQR) } \\
\text { Mean }(95 \% \mathrm{Cl})\end{array}$ & $\begin{array}{l}2(2-3) \\
2.5(2.3-2.8)\end{array}$ & $\begin{array}{l}2(2-3) \\
2.9(2.4-3.4)\end{array}$ \\
\hline BTP Intensity (NRS) ${ }^{b}$ & $\begin{array}{l}\text { Median (IQR) } \\
\text { Mean }(95 \% \mathrm{Cl})\end{array}$ & $\begin{array}{l}7(7-8) \\
7.5(7.2-7.7)\end{array}$ & $\begin{array}{l}8(7-9) \\
7.9(7.6-8.2)^{b}\end{array}$ \\
\hline BTP duration (days) ${ }^{a}$ & $\begin{array}{l}\text { Median (IQR) } \\
\text { Mean }(95 \% \mathrm{CI})\end{array}$ & $\begin{array}{l}15(7-27) \\
21.9(14.6-29.2)\end{array}$ & $\begin{array}{l}6(3-11) \\
21.0(3.6-38.6)\end{array}$ \\
\hline Predominant BTP type ${ }^{a}$ & $\begin{array}{l}\text { Not predictable } \\
\text { Predictable }\end{array}$ & $\begin{array}{l}85(70.8 \%) \\
35(29.2 \%)\end{array}$ & $\begin{array}{l}37(62.7 \%) \\
22(37.3 \%)\end{array}$ \\
\hline Spike reaching time ${ }^{c}$ & $\begin{array}{l}\leq 10 \text { minutes } \\
>10 \text { minutes }\end{array}$ & $\begin{array}{l}98(81.7 \%) \\
22(18.3 \%)\end{array}$ & $\begin{array}{l}35(59.3 \%)^{\mathrm{c}} \\
24(40.7 \%)^{\mathrm{c}}\end{array}$ \\
\hline Type of BTPa & $\begin{array}{l}\text { Mixed } \\
\text { Neuropathic } \\
\text { Nociceptive }\end{array}$ & $\begin{array}{l}69(57.5 \%) \\
19(15.8 \%) \\
32(26.7 \%)\end{array}$ & $\begin{array}{l}31(52.5 \%) \\
2(3.4 \%) \\
26(44.1 \%)\end{array}$ \\
\hline Trigger event (if predictable) ${ }^{a}$ & $\begin{array}{l}\text { Ingestion of food } \\
\text { Stool } \\
\text { Movement } \\
\text { Procedures } \\
\text { Cough }\end{array}$ & $\begin{array}{l}7(5.8 \%) \\
1(0.8 \%) \\
22(18.3 \%) \\
3(2.5 \%) \\
2(1.7 \%)\end{array}$ & $\begin{array}{l}3(5.1 \%) \\
\text { I }(1.7 \%) \\
15(25.4 \%) \\
1(1.7 \%) \\
3(5.1 \%)\end{array}$ \\
\hline BTcP Pain sites ${ }^{a}$ & $\begin{array}{l}\text { Abdominal } \\
\text { Lower limbs } \\
\text { Pelvis } \\
\text { Dorsal spine } \\
\text { Lumbar spine } \\
\text { Chest }\end{array}$ & $\begin{array}{l}28(23.3 \%) \\
17(14.2 \%) \\
10(8.3 \%) \\
20(16.7 \%) \\
29(24.2 \%) \\
31(25.8 \%)\end{array}$ & $\begin{array}{l}9(15.3 \%) \\
12(20.3 \%) \\
12(20.3 \%) \\
10(16.9 \%) \\
17(28.8 \%) \\
7(11.9 \%)\end{array}$ \\
\hline
\end{tabular}

Notes: ${ }^{a} P>0.05$ (group A vs group B). ${ }^{b} P=0.04 .{ }^{c} P<0.002$ (group A vs group B).

Abbreviations: BGP, background pain; BTcP, breakthrough cancer pain. 
Table 3 Treatment Characteristics in the Population Treated Only with OxyIR/Par for Background Pain $(n=120)$ and in Combination with Other Opioid Drugs $(n=59)$

\begin{tabular}{|c|c|c|c|}
\hline & & Group A (120) & Group B (59) \\
\hline Other opioids & & 0 & $59(100 \%)$ \\
\hline \multicolumn{3}{|l|}{ Hydromorphone } & I (I.7\%) \\
\hline \multicolumn{3}{|l|}{ Morphine slow release } & I (I.7\%) \\
\hline \multicolumn{3}{|l|}{ Oxycodone slow release } & $6(10.2 \%)$ \\
\hline \multicolumn{3}{|l|}{ Codeine+acetaminophen } & $3(5.1 \%)$ \\
\hline \multicolumn{3}{|l|}{ Oxycodone+naloxone } & $26(44.1 \%)$ \\
\hline \multicolumn{3}{|l|}{ Tapentadol } & $2(3.4 \%)$ \\
\hline \multicolumn{3}{|l|}{ Tramadol } & $2(3.4 \%)$ \\
\hline \multicolumn{3}{|l|}{ Morphine IR } & $2(3.4 \%)$ \\
\hline \multicolumn{3}{|l|}{ Fentanyl TD } & 17 (28.8\%) \\
\hline \multicolumn{3}{|l|}{ Buprenorphine TD } & $2(3.4 \%)$ \\
\hline Non-opioid & No & $98(81.7 \%)$ & $48(81.3 \%)$ \\
\hline analgesics drugs ${ }^{a}$ & Yes & $22(18.3 \%)$ & II (I8,7\%) \\
\hline \multirow[t]{3}{*}{ Drugs $^{c}$} & NSAID & $12(10.0 \%)$ & $6(10.2 \%)$ \\
\hline & COXIB & I (0.8\%) & $0(0.0 \%)$ \\
\hline & Paracetamol & $10(8.3 \%)$ & $5(8.5 \%)$ \\
\hline \multirow{2}{*}{$\begin{array}{l}\text { OxylR/Par } \\
\text { as needed }^{\text {a }}\end{array}$} & No & II5 (95.8\%) & 44 (74.6\%) \\
\hline & Yes & $5(4.2 \%)$ & 15 (25.4\%) \\
\hline \multirow{2}{*}{$\begin{array}{l}\text { OxylR/Par dose } \\
(\mathrm{mg})^{\mathrm{a}}\end{array}$} & Median (IQR) & $10(5,15)$ & $10(7.5,20)$ \\
\hline & Mean $(95 \% \mathrm{Cl})$ & $12.0(10.5-13.4)$ & $13.1(11.0-15.1)$ \\
\hline \multirow{8}{*}{$\begin{array}{l}\mathrm{N} \text { of } \\
\text { administration/die }\end{array}$} & I & I (0.8\%) & $17(28.8 \%)$ \\
\hline & 2 & 47 (39.2\%) & 17 (28.8\%) \\
\hline & 3 & $55(45.8 \%)$ & 18 (30.5\%) \\
\hline & 4 & $13(10.8 \%)$ & $6(10.2 \%)$ \\
\hline & 5 & $0(0.0 \%)$ & I (I.7\%) \\
\hline & 6 & $4(3.3 \%)$ & $0(0.0 \%)$ \\
\hline & Median (IQR) & $3(2,3)$ & $2(I, 3)$ \\
\hline & Mean $(95 \% \mathrm{Cl})$ & $2.8(2.6-3.0)$ & $2.3(2.0-2.5)$ \\
\hline \multirow{2}{*}{$\begin{array}{l}\text { Mean daily oxycodone dose of } \\
\text { OxyIR/Par }\end{array}$} & Median (IQR) & $30(20-40)$ & $20(10-50)$ \\
\hline & Mean $(95 \% \mathrm{Cl})$ & $32.7(28.6-36.8)$ & $31.4(24.7-38.0)$ \\
\hline \multirow{2}{*}{$\begin{array}{l}\text { Mean opioid doses } \\
\text { OME }(\mathrm{mg})^{\mathrm{b}}\end{array}$} & Median (IQR) & $45(30-60)$ & $119(75-153)^{b}$ \\
\hline & Mean $(95 \% \mathrm{Cl})$ & 49.1 (42.9-55.2) & I $68.7(\mid \text { I } 5.1-222.3)^{b}$ \\
\hline
\end{tabular}

Notes: ${ }^{a} P>0.05$ (group A vs group B). ${ }^{b} P<0.00$ I (group A vs group B). Patients could receive more than one non-opioid treatment.

$57.0 \%)$ and nociceptive $(\mathrm{n}=55,30.7 .6 \%)$ with an important neuropathic component $(\mathrm{n}=22,12.3 \%)$ (mixed + neuropathic $73.4 \%$ in group A vs $61.0 \%$ in group $\mathrm{B}, P=0.02$ ). The BGP sites were mainly vertebrae, abdomen $(25.8 \%$ in group $\mathrm{A}$ vs $16.9 \%$ in group $\mathrm{B}, P=0.25)$ and chest $(24.2 \%$ in group $\mathrm{A}$ vs $13.6 \%$ in group $\mathrm{B}, P=0.15)$, with abdomen + chest highly represented $(50 \%$ in group A vs $30.5 \%$ in group $\mathrm{B}, P=0.01$ ).

BTcP in group A had a significant faster onset vs group $\mathrm{B}$ (less than 10 minutes in $81.7 \%$ of patients, compared to $59.3 \%$ of patients in group $\mathrm{B}, P=0.002)$. $\mathrm{BTcP}$ was less frequent with no significant difference (average 2.5 
Table 4 Adverse Reaction Reported by the Population Treated Only with OxylR/Par for Background Pain $(n=120)$ and in Combination with Other Opioid Drugs $(n=59)$

\begin{tabular}{|l|l|l|}
\hline & Group A ( 120) & Group B (59) \\
\hline No adverse events & $28(96.5 \%)$ & $26(100.0 \%)$ \\
Adverse events & $I(3.5 \%)$ & $0(0.0 \%)$ \\
Missing & 91 & 33 \\
Headache & $0(0 \%)$ & $0(0 \%)$ \\
Mental confusion & $0(0 \%)$ & $0(0 \%)$ \\
Nausea & $0(0 \%)$ & $0(0 \%)$ \\
Constipation & $1(0.8 \%)$ & $0(0 \%)$ \\
Other & $0(0 \%)$ & $0(0 \%)$ \\
\hline
\end{tabular}

episodes/die; $95 \% \mathrm{CI}=2.3-2.8$ vs 2.9 episodes/die; $95 \%$ $\mathrm{CI}=2.4-3.4$ in group $\mathrm{B}, P=0.21)$, and less intense ( 7.5 NRS; $95 \% \mathrm{CI}=7.2-7.7$ vs $7.9 \mathrm{NRS} ; 95 \% \mathrm{CI}=7.6-8.2$ in group $\mathrm{B}, P=0.04)$, $\mathrm{BTcP}$ was not predictable in $70.8 \%$ of patients in group $\mathrm{A}$ and in $62.7 \%$ of group $\mathrm{B}(P=0.35)$ (Table 2).

Group A showed a significant higher Karnofsky Index, average $=70.3(95 \% \mathrm{CI}=67.2-73.5 ;$ median $=70$, $\mathrm{CI}=60-80)$ compared to group $\mathrm{B}$, average $=58.3(95 \%$ $\mathrm{CI}=53.4-63.2 ;$ median $=50, \mathrm{CI}=45-70) \quad(P<0.001)$ and was constituted mainly by outpatients and hospital inpatients $(77.5 \%$ vs $42.4 \%, P<0.001$, compared to group B). Group B expressed a lower Karnofsky Index that was consistent with a different distribution of patients, with home palliative care representing $44 \%$ of the cases.

In group A, OxyIR/Par was administered $2.8(95 \%$ $\mathrm{CI}=2.6-3.0)$ times a day, at mean oxycodone dosage $12.0 \mathrm{mg}$ (95\% CI=10.5-13.4) (Table 3), with statistically significant differences for types of pain (mixed (56.7\%), nociceptive $(36.6 \%)$ or neuropathic $(16.7 \%), P=0.009)$. The mean daily oxycodone dose of OxyIR/Par was $32.7 \mathrm{mg}$ (95\% $\mathrm{CI}=28.6-36.8)$, which corresponds with $49.1 \mathrm{mg} /$ die $(\mathrm{CI}=42.9-55.2)$ OME. In group $\mathrm{B}$, the mean daily oxycodone dose of OxyIR/Par was $31.4 \mathrm{mg}(95 \%$ $\mathrm{CI}=24.7-38.0)$, with a mean dosage of $13.1 \mathrm{mg}(95 \%$ $\mathrm{CI}=11.0-15.1)$ and $2.3(95 \% \mathrm{CI}=2.0-2.5)$ administrations per day ( $P=0.73$ difference between group $\mathrm{A}$ and $\mathrm{B})$, but the average of the total daily dose of OME was $168.7 \mathrm{mg} /$ die $(95 \% \mathrm{CI}=115.1-222.3) \quad(P<0.001$ difference between group $\mathrm{A}$ and $\mathrm{B}$ ) for the concomitant treatment of oxycodone slow release (alone or in combination with naloxone) or fentanyl TTS (Table 3).

\section{Adverse Effects}

No adverse effects of severe intensity related to BGP treatments were reported (Table 4). Lots of missing data about adverse events were found in the enrolled cohort ( 91 and 33 missing data were reported in Group A and B, respectively). Only one case of constipation was assessed in Group A.

\section{Discussion}

International guidelines traditionally recommended treating chronic cancer pain according to pain intensity. ${ }^{2,25}$ More recently, other parameters (eg, pain type, other treatments, co-morbidities) have been suggested to be considered in the therapy choice process. ${ }^{2,4}$ Indeed, it was suggested that the unsuccessful analgesia was depending on the complexity of cancer pain and clinical characteristics, and that therapeutic management of cancer pain should be addressed to the different patterns of pain with an association of a few different drugs directed against these different pain characteristics using a synergistic mechanism of action. ${ }^{10}$

By this secondary analysis a cohort of patients with higher Karnofsky was well managed with OxyIR/Par alone with a low oral morphine equivalent dose significantly lower (OME level $=49.1 \mathrm{mg} / \mathrm{die}$ vs $168.7 \mathrm{mg} / \mathrm{die}$, $P<0.001$ OME) than those of group B. Also Group B was characterized by lower Karnofsky (mean 58.3) in line with the prevalent setting of assessment that was palliative care $(44,1 \%)$ was managed with OxyIR/Par in combination with long-acting opioids. Noteworthy, OxyIR/Par was effective in both groups, with higher or lower functional status with or without the need for long-acting opioids. The need for OxyIR/Par in addition to other opioids confirms findings that emerged in the study of Sima et al, ${ }^{15}$ where the association of OxyIR/Par had relieved bone metastases pain in patients with concomitant high doses of slow-release opioids. Moreover, some authors have recognized the benefit of opioid/non-opioid combinations, such as oxycodone and acetaminophen, in the treatment of moderate-severe pain in non-cancer patients and in a few studies on cancer patients, the same association was able to provide satisfactory analgesia in heavily opioid pretreated patients. ${ }^{15}$

Recent studies have emphasized that, not being cancer pain a homogenous entity, an accurate pain assessment and classification is essential for obtaining satisfactory and individualized pain management. ${ }^{26,27}$ Despite these recommendations, what is happening in the real world is 
the failure of analgesic therapy in a relevant rate of cancer patients. $^{28-30}$

It can be argued that therapeutic management of cancer pain should be possibly multimodal, flexible, and capable of intercepting not only the different components of the cancer pain but also the expression of continuous tumor-host interactions in different stages of cancer disease. ${ }^{6}$ The oral fixeddose combination of OxyIR/Par could satisfy some need in the management of cancer pain, such as the use of lower dosages thanks to the synergistic mechanisms of action, as well as the more effective pain relief for different pain mechanisms, matching with the most mixed pain prevalence of cancer pain, and the versatility of use as around the clock or as a needed treatment due to its immediate-release formulation. ${ }^{13,15}$ Indeed, in this secondary analysis, the OxyIR/Par, alone or in combination with long-acting opioids, was effective for all types of pain (mixed, nociceptive, or neuropathic), as shown in Table 2. Although all enrolled patients had BTcP and the difference in BGP intensity between the two groups of patients was not significant (3.2 vs $2.9, P=017$ ), the groups presented different characteristics (such as performance status, place of visit and setting, and the total amount of opioids), probably depending on the differences in disease progression. Indeed, group B had worse BTcP characterized by higher frequency (2.9/die), intensity (NRS 7.9), predictability, and longer onset time ( $>10$ minutes), while in group A, BTcP manifested with a lower number of episodes per day (2.5 episodes/die), lower intensity (7.5 NRS), and faster onset time (less than 10 minutes in $81.7 \%$ ). It is likely that these patients were on an early stage of the disease and the pain syndrome was less aggressive, they were mainly outpatients treated in an ambulatory setting, and this maybe justifies the required lower doses of opioids for adequate background analgesia.

Pain sites were mostly in the abdominal and thoracic area, in fact lung and gastrointestinal tumors were the more frequent primary tumors, involving mixed and neuropathic mechanisms. OxyIR/Par was shown to be effective both in nociceptive and neuropathic components of mixed type pain, which represents $70 \%$ of cancer pain ${ }^{2}$.

Finally, OxyIR/Par combination was found to control pain alone and in combination even for long periods of time (over 1 month with OxyIR/Par and about 2 months in combination with other opioids in difficult patients, as shown in Table 2). In the latter case (Group B) this data, together with a higher daily dose, could be justified by the advanced cancer stage of the disease.
To the best of our knowledge, this study has provided formal proof that an OxyIR/Par combination can be successfully used for the management of moderate-severe BGP in cancer opioid patients, and has the versatility of the association to permit an individualized approach to pain treatment patients with the lowest doses of antalgic drugs. ${ }^{31,32}$

Limitations of this work are represented by it being a secondary analysis of a larger study with a different aim focused on BTcP and, also, by the nature of the population, afflicted by BTcP and, hence, by intrinsic complexity.

Although our data will need to be confirmed in larger studies about OxyIR/Par in cancer patients with pain, this study has the advantage of being based on study conditions close to routine clinical practice. Therefore, our data might provide useful information for better management of antalgic control in a well-selected population of patients, benefitting from low doses of opioids in combination with acetaminophen, that may facilitate targeted treatment and outcome optimization. Moreover, for patients in the palliative phase of their cancer, it is necessary to constantly monitor the patient's symptom painrelieving treatments. The flexibility of a fixed combination of OxyIR/Par may not be enough and not a practical option at the end cancer stage.

\section{Conclusion}

In conclusion, key messages that emerge from our study are:

- The oral fixed combination OxyIR/Par provided an adequate level of analgesia for moderate-severe background cancer pain, in different cohorts of cancer patients with different performance statuses, both in the ambulatory setting and palliative one.

- The low dosage of fixed combination OxyIR/Par was effective, with at least three administrations per day and approximately at the same dose both in outpatient cancer patients as well as in-home care settings, in association with other opioids.

- The fixed combination of oxycodone/acetaminophen is a versatile therapeutic option providing cancer pain control alone or in association with other opioids, given as needed or not.

- The synergistic effect of the association of oxycodone and acetaminophen could provide effective control of all types of pain, mixed/nociceptive/ neuropathy - cancer pain at low doses. 


\section{Acknowledgments}

The study was sponsored by Molteni, Italy. Data were independently analyzed by the IOPS MS Scientific Committee. Data were independently managed by authors. The authors wish to thank the members of the Italian IOPS-MS study group for their contribution to the study.

\section{Disclosure}

Professor Silvia Natoli serves in the advisory board/speakers' bureau for and receives personal fees from Grunenthal Italia, Angelini, Sandoz, and Mylan, outside the submitted work. The authors report no other conflicts of interest in this work.

\section{References}

1. Organization WH. Cancer Pain Relief. World Health Organization; 1986. https://apps.who.int/iris/handle/10665/43944. Accessed July 22, 2020.

2. Linee Guida Terapia Del Dolore In Oncologia. AIOM. 2018. Accessed July 22, 2020. https://www.aiom.it/linee-guida-aiom-2018terapia-del-dolore-in-oncologia/.

3. Caraceni A, Hanks G, Kaasa S, et al. Use of opioid analgesics in the treatment of cancer pain: evidence-based recommendations from the EAPC. Lancet Oncol. 2012;13(2):e58-68. doi:10.1016/S14702045(12)70040-2

4. Fallon M, Giusti R, Aielli F, et al. Management of cancer pain in adult patients: ESMO Clinical Practice Guidelines. Ann Oncol. 2018;29(Suppl 4):iv166-iv191. doi:10.1093/annonc/mdy152

5. Kwon JH. Overcoming barriers in cancer pain management. $J$ Clin Oncol. 2014;32(16):1727-1733. doi:10.1200/JCO.2013.52.4827

6. Mercadante S, Portenoy RK. Opioid poorly-responsive cancer pain. Part 3. Clinical strategies to improve opioid responsiveness. J Pain Symptom Manage. 2001;21(4):338-354. doi:10.1016/s0885-3924(01) 00250-0

7. Greco MT, Roberto A, Corli O, et al. Quality of cancer pain management: an update of a systematic review of undertreatment of patients with cancer. J Clin Oncol. 2014;32(36):4149-4154. doi:10.1200/ JCO.2014.56.0383

8. Reis-Pina P, Lawlor PG, Barbosa A. Adequacy of cancer-related pain management and predictors of undertreatment at referral to a pain clinic. J Pain Res. 2017;10:2097-2107. doi:10.2147/JPR.S139715

9. Gatti A, Sabato AF, Carucci A, Bertini L, Mammucari M, Occhioni R. Adequacy assessment of oxycodone/paracetamol (acetaminophen) in multimodal chronic pain: a prospective observational study. Clin Drug Investig. 2009;29(Suppl 1):31-40. doi:10.2165/ 0044011-200929001-00005

10. Mao J, Gold MS, Backonja M. Combination drug therapy for chronic pain: a call for more clinical studies. J Pain. 2011;12(2):157-166. doi:10.1016/j.jpain.2010.07.006

11. Gilron I, Jensen TS, Dickenson AH. Combination pharmacotherapy for management of chronic pain: from bench to bedside. Lancet Neurol. 2013;12(11):1084-1095. doi:10.1016/S1474-4422(13)70193-5

12. Gammaitoni AR, Galer BS, Bulloch S, et al. Randomized, double-blind, placebo-controlled comparison of the analgesic efficacy of oxycodone $10 \mathrm{mg} /$ acetaminophen $325 \mathrm{mg}$ versus controlled-release oxycodone $20 \mathrm{mg}$ in postsurgical pain. $J$ Clin Pharmacol. 2003;43(3):296-304. doi:10.1177/0091270003251147

13. Gatti A, Sabato E, Di Paolo AR, Mammucari M, Sabato AF. Oxycodone/paracetamol: a low-dose synergic combination useful in different types of pain. Clin Drug Invest. 2010;30(Suppl 2):3-14. doi:10.2165/1158414-S0-000000000-00000
14. Gaskell H, Derry S, Moore RA, McQuay HJ. Single dose oral oxycodone and oxycodone plus paracetamol (acetaminophen) for acute postoperative pain in adults. Cochrane Database Syst Rev. 2009;3:CD002763. doi:10.1002/14651858.CD002763.pub2

15. Sima L, Fang WX, Wu XM, Li F. Efficacy of oxycodone/paracetamol for patients with bone-cancer pain: a multicenter, randomized, double-blinded, placebo-controlled trial. J Clin Pharm Ther. 2012;37(1):27-31. doi:10.1111/j.1365-2710.2010.01239.x

16. Leppert W. Role of oxycodone and oxycodone/naloxone in cancer pain management. Pharmacol Rep. 2010;62(4):578-591. doi:10.1016/s1734-1140(10)70316-9

17. Olkkola KT, Kontinen VK, Saari TI, Kalso EA. Does the pharmacology of oxycodone justify its increasing use as an analgesic? Trends Pharmacol Sci. 2013;34(4):206-214. doi:10.1016/j.tips.2013.02.001

18. De Santis S, Borghesi C, Ricciardi S, et al. Analgesic effectiveness and tolerability of oral oxycodone/naloxone and pregabalin in patients with lung cancer and neuropathic pain: an observational analysis. Onco Targets Ther. 2016;9:4043-4052. doi:10.2147/OTT. S108144

19. Gao T, Zhu H, Zhang C, et al. Efficacy of acetaminophen with and without oxycodone for analgesia in non-operative treatment of extremity fractures in adults: protocol for a double-blind randomized clinical trial. Trials. 2019;20(1):510. doi:10.1186/s13063-019-3579-x

20. Mercadante S, Marchetti P, Cuomo A, et al. Factors Influencing the Clinical Presentation of Breakthrough Pain in Cancer Patients. Cancers. 2018;10:6. doi:10.3390/cancers10060175

21. Løhre ET, Klepstad P, Bennett MI, et al. From "Breakthrough" to "Episodic" Cancer Pain? A european association for palliative care research network expert delphi survey toward a common terminology and classification of transient cancer pain exacerbations. J Pain Symptom Manage. 2016;51(6):1013-1019. doi:10.1016/j. jpainsymman.2015.12.329

22. Mercadante S, Lazzari M, Reale C, et al. Italian Oncological Pain Survey (IOPS): a multicentre Italian study of breakthrough pain performed in different settings. Clin J Pain. 2015;31(3):214-221. doi:10.1097/AJP.0000000000000161

23. Mercadante S, Adile C, Torta R, et al. Meaningful cut-off pain intensity for breakthrough pain changes in advanced cancer patients. Curr Med Res Opin. 2013;29(1):93-97. doi:10.1185/ 03007995.2012.755120

24. Mercadante S, Adile C, Masedu F, Marchetti P, Costanzi A, Aielli F. Factors influencing the use of opioids for breakthrough cancer pain: a secondary analysis of the IOPS-MS study. Eur J Pain. 2019;23 (4):719-726. doi:10.1002/ejp.1339

25. WHO. WHO's Cancer Pain Ladder for Adults. WHO. https://www. who.int/cancer/palliative/painladder/en/. Accessed July 22, 2020.

26. Hui D, Bruera E. A personalized approach to assessing and managing pain in patients with cancer. J Clin Oncol. 2014;32(16):1640-1646. doi:10.1200/JCO.2013.52.2508

27. Caraceni A, Shkodra M. Cancer Pain Assessment and Classification. Cancers. 2019;11:4. doi:10.3390/cancers 11040510

28. Mercadante S. The Patient with Difficult Cancer Pain. Cancers. 2019;11:4. doi:10.3390/cancers11040565

29. Niscola P, Tendas A, Scaramucci L, et al. Pain in malignant hematology. Exp Rev Hematol. 2011;4(1):81-93. doi:10.1586/ ehm.10.79

30. Mercadante S. Reviewing without a Clinical Background Is Detrimental for Cancer Pain Management. Cancers. 2019;11:7. doi:10.3390/cancers11071005

31. Grond S, Radbruch L, Meuser T, Loick G, Sabatowski R, Lehmann KA. High-dose tramadol in comparison to low-dose morphine for cancer pain relief. J Pain Symptom Manage. 1999;18 (3):174-179. doi:10.1016/s0885-3924(99)00060-3

32. Mercadante S, Porzio G, Ferrera P, et al. Low morphine doses in opioid-naive cancer patients with pain. J Pain Symptom Manage. 2006;31(3):242-247. doi:10.1016/j.jpainsymman.2006.01.001 


\section{Publish your work in this journal}

Cancer Management and Research is an international, peer-reviewed open access journal focusing on cancer research and the optimal use of preventative and integrated treatment interventions to achieve improved outcomes, enhanced survival and quality of life for the cancer patient.
The manuscript management system is completely online and includes a very quick and fair peer-review system, which is all easy to use. Visit http://www.dovepress.com/testimonials.php to read real quotes from published authors. 